\title{
Ocular Health Status and Causes of Enrolment into Special Schools in Osun State, Nigeria
}

\author{
Michaeline Isawumi, ${ }^{1, *}$ and Folasade Akinsola ${ }^{2}$ \\ ${ }^{1}$ Department of Surgery, Osun State University, Osogbo, Nigeria \\ ${ }^{2}$ Department of Ophthalmology, Lagos University Teaching Hospital, Lagos, Nigeria \\ "Corresponding author: Michaeline Isawumi, Department of Surgery, College of Health Sciences, Osun State University, Osogbo, PMB 4494 Nigeria. Tel: +234-8033912103, E-mail: \\ michaeline.isawumi@uniosun.edu.ng
}

Received 2015 December 06; Revised 2016 February 28; Accepted 2016 December 06.

\begin{abstract}
Background: Knowledge of the status of eye diseases among students' enrolled in the special schools would assist in planning preventive and treatment strategies.

Objectives: To determine the types and causes of ocular morbidity leading to enrolment of students in special schools of Osun state. Methods: We conducted a cross-sectional study by utilizing a total-sampling-technique on students attending all 8 special primary and integrated secondary schools to find out the common ophthalmic diseases between July and September 2013. Teachers' registers, oral interview and clinical examination were used to obtain data. The data were analyzed by descriptive statistics through SPSS 17 software.

Results: Four hundred and seventy-two (472) students between the ages of 4 and 36 years with mean of $13.7 \pm 4.7$ were examined. Two hundred and seventy-six (58.5\%) were males and one hundred-ninety- six were females. Fathers' occupation were mostly farmers 142 (30.1\%) and Artisans 133 (28.2\%). Abnormal ocular findings were seen in 9.9\% of students. The prevalence of blindness was $4.7 \%$ [95\% Confidence Interval (CI) 2.7 - 6.6]. Anatomical causes of blindness were corneal scarring (2.1\%) especially post measles keratopathy, whole globe disorders (1.1\%), toxoplasma chorioretinal scars and maculopathies (0.6\%), amblyopia/uncorrected refractive errors $(0.4 \%)$ and cortical visual impairment $(0.2 \%)$. The prevalence of visual impairment was $1.4 \%$ [CI $0.0-1.7]$, with cataracts and refractive error being the most common causes. Other findings included nystagmus ( $0.2 \%)$, vernal conjunctivitis ( $0.4 \%)$, and pigmentary retinopathy (4.2\%). Ocular pathologies occurred most frequently among the lower socio-economic group $\left(\chi^{2} 169.69, \mathrm{P}<0.001\right)$.

Conclusions: The common causes of ocular diseases leading to enrolment are avoidable. Mandatory eye examination at birth, preschool years and school age is needed for early detection and intervention. Health education, adequate nutrition, and immunization are required for prevention.
\end{abstract}

Keywords: Eye, Health Status, Education Special

\section{Introduction}

People with special needs have not been enjoying accessible general health facilities in this part of the world [1]. There are also no planned or routine ophthalmological services for these schools in the country or this state [2]. Some studies have found ocular problems among them such as cataract, glaucoma, refractive errors, and retinal diseases [3-7]. A child's overall development can be affected by disabilities including visual impairment. In subSaharan Africa, the most common childhood eye diseases leading to blindness are usually avoidable [3]. Studies have shown that visual pathway pathology is sometimes more common among children or persons with disabilities than those with typical development [4-6].

In Saarland, "optic atrophy (17.5\%), ocular albinism (11.9\%), stage IV and V of retinopathy of prematurity (11.1\%), tapetoretinal dystrophies with related syndromes (8.7\%), and high myopia (7.9\%)" were the causes of blindness and visual impairment in those with multiple disabilities [7]. The types of disabilities monitored by the metropolitan atlanta developmental disabilities surveillance program (MADDSP) in the USA included mental retardation, cerebral palsy, hearing loss, vision impairment and autism spectrum disorders [8].

Osun State is a state in southwestern Nigeria located in the tropical rainforest belt. General health evaluations are not done specifically for students in special schools apart from the yearly programmed services rendered by the department of community health of the Ladoke Akintola university of technology teaching hospital (LTH), Osogbo, Nigeria. There are no planned or routine ophthalmological services for these schools, also. These schools are special education schools where children with hearing, physical, visual, and intellectual disabilities are being taught reading, writing and communication skills. Only one of these schools (owned by missionaries) has facilities for learning and training in some vocation. 


\section{Objectives}

This study is therefore designed to find out the information about the prevalent eye diseases among these special students leading to their enrolment in these schools. Measures to prevent the common eye problems will be suggested for incorporation into primary health care and the school health care services of the state.

\section{Methods}

Osun state is located in the Southwestern part of Nigeria with an estimated population of over 3.7 million. The people are mainly farmers as well as live in rural dwellings. The climate is mainly tropical, and vegetation is that of southern lowlands and tropical rain forest. It is made up of 30 local government areas spread across 3 senatorial districts [9].

In each of these districts is located at least one special primary school. The secondary schools (integrated) are located in Osogbo, the state capital.

We conducted a cross-sectional survey utilizing a total sampling technique of 472 students from 6 primary schools for children with disabilities located in Modakeke, Ikoyi, Ipetumodu, Iwo, Osogbo and Ikirun; and 2 integrated secondary schools for typically developing and children with disabilities in Osun State of Nigeria. The survey was performed from July to September 2013. Informed consent was obtained from the head teachers and from the students. Their cooperations were determined and the purpose of study was explained to them. The teachers were recruited and trained to assist the nurse in visual acuity (VA) testing. A pilot study was done among twenty normal school children after whom necessary changes were made. The dates for examination were then confirmed. The teachers obtained demographic data such as age, gender, father's occupation, and socio-economic status from their school register. If there were causes of the disabilities, it would record. Visual acuity (VA) was tested for by the nurse who was assisted by the classroom teacher. The VA test was done in a well illuminated hall or outside the classroom during the day time between the hours of 8:30 am and 12 noon. Special education teachers assisted in the use of sign language and interpretation during VA testing and ocular examination by the ophthalmologist. The illiterate E chart was read from a distance of 6 meters or Lea Symbols (optotype charts) at 3 meters. Visual acuity was measured one eye at a time.

The world health organization (WHO) modified form for childhood blindness was used where $6 / 6$ to $6 / 18$ is normal (Normal vision), $<6 / 18$ to $6 / 60$, and $<6 / 60$ to $3 / 60$ (Visual impairment-VI and severe visual impairment SVI), and $<3 / 60$ to no light perception NPL (Blindness). Vision was recorded according to the WHO categories of visual impairment and blindness and estimated vision was recorded for those who were non-verbal [10].

The ophthalmologist assessed the result of the VA. If $<6 / 9$ and improved with pinhole, this was to be suggestive of refractive error. This was to be suggestive of refractive error and such students were booked for refraction. Anterior segment examination was performed using a bright pen torch while the posterior segment was examined using Heine beta150 ophthalmoscope through undilated pupils. For those in whom better view was required, the pupils were dilated with $1 \%$ tropicamide (Mydriacyl by Alcon). Extra ocular muscle motility was assessed. Hirschberg's test and free prisms were used to estimate the degree of strabismus. The causes and types of eye conditions were noted. Cycloplegic refraction was performed on students by the author in a darkened room. Cycloplegia was achieved using a combination of tropicamide and $1 \%$ phenyl ephedrine eye drops. Post mydriatic tests were carried out in a well illuminated room on the follow up visits. Glasses were then prescribed where vision improved with refraction. Low vision aids was ordered where necessary.

\subsection{Data Management}

Information collected was recorded into a data collection form. Data was entered and reentered for validation. Analysis was done using the statistical package for social sciences (SPSS) version 17. Descriptive statistics was carried out to determine frequencies of variables while P values < 0.05 and $95 \%$ confidence limits for test of significance were determined.

\section{Results}

Four hundred and seventy two (472) students were examined from 6 public primary schools and 2 integrated public secondary schools for children with disabilities. The males were 276 (58.5\%, CI 54.0 - 63.0) and females 196 (41.5\% CI 37.1 - 46.0) with a male to female ratio of 1.4: 1. Ages ranged between 4 and 36 years with a mean of $13.7+4.7$ years. The distribution of the fathers' occupation shows that the Artisans (low socio economic group) children had the most frequently occurring ocular manifestations, $\chi^{2}$ 169.69, $\mathrm{P}<0.001$ (Table 1).

The visual acuity distribution is shown in Table 2.

The proportion of students who could not have VA assessed in a typical manner was mostly among the students with Down syndrome and those with intellectual disabilities, 18(3.8\%). The types of disabilities found in decreasing 
Table 1. Distribution of Ocular Presentation Among the Fathers' Occupation ${ }^{\mathrm{a}}$

\begin{tabular}{lccc}
\hline & \multicolumn{3}{c}{ Ocular Presentations } \\
\cline { 2 - 4 } Fathers' Occupation & Normal (\%) & Abnormal (\%) & Total (\%) \\
\hline Trader & 84 & $7(1.5)$ & $91(19.3)$ \\
\hline Farmer & 130 & $12(2.5)$ & $142(30.1)$ \\
\hline Artisan & 113 & $20(4.2)$ & $133(28.2)$ \\
\hline Civil Servant & 75 & $7(1.5)$ & $82(17.4)$ \\
\hline Clergy Man & 10 & $1(0.2)$ & $11(2.3)$ \\
\hline Unknown & 13 & $0(0.0)$ & $13(2.8)$ \\
\hline Total & $425(90 \%)$ & $47(9.9 \%)$ & $472(100 \%)$ \\
\hline
\end{tabular}

${ }^{\mathrm{a}} \chi^{2} 169.69, \mathrm{P}<0.001$.

Table 2. The Presenting Visual Acuity Distribution in the Better Eye of the Students ${ }^{\mathrm{a}}$

\begin{tabular}{lcc}
\hline Visual Acuity & Frequency (\%) & $\begin{array}{c}\text { 95\% Confidence Interval } \\
(\mathbf{C I})\end{array}$ \\
\hline $\mathbf{6 / 6}-\mathbf{6} / \mathbf{1 8}$ & $425(90.0)$ & $87.3-92.7$ \\
$<\mathbf{6 / 1 8}-\mathbf{6} / \mathbf{6 0}$ & $4(0.8)$ & $0.0-1.7$ \\
\hline$<\mathbf{6} / \mathbf{6 0}-\mathbf{3} / \mathbf{6 0}$ & $3(0.6)$ & $-0.1-1.3$ \\
\hline$<\mathbf{3 / 6 0}-\mathbf{N P L}$ & $22(4.7)$ & $2.7-6.6$ \\
\hline $\begin{array}{l}\text { Believed } \\
\text { sighted/(Uncooperative) }\end{array}$ & $18(3.8)$ & $2.1-5.5$ \\
\hline Total & $472(100 \%)$ & \\
\hline
\end{tabular}

${ }^{\mathrm{a}}$ Visual impairment 7/472 (1.4\%), 95\% confidence interval $(\mathrm{CI})=0.4$ - 2.6.

order were hearing, physical, intellectual and visual (Table 3).

Table 3. Frequency Distribution of Types of Disability and Co-Existence with Blind ness

\begin{tabular}{|ccc|}
\hline Types of Disability & Frequency & $\%$ \\
\hline Hearing & 317 & 67.2 \\
\hline Physical & 23 & 4.9 \\
\hline Intellectual & 110 & 23.3 \\
\hline Visual & 22 & 4.7 \\
\hline Total & 472 & $100 \%$ \\
\hline Co-existing disabilities with blindness & & \\
\hline Hearing & 2 & 9.0 \\
\hline Physical & 1 & 4.5 \\
\hline Intellectual & 3 & 13.5 \\
\hline Visual (only) & 16 & 72.7 \\
\hline Total & 22 & $100 \%$ \\
\hline
\end{tabular}

There were also children with more than one type of disability. Twenty two students (4.7\%) were bilaterally blind while 2 were unilaterally blind giving a total of 46 blind eyes. The main cause of blindness was corneal diseases. The causes of blindness were from anatomical disorders 14 (2.9\%), especially following measles infections, congenital abnormalities, amblyopia from uncorrected aphakia, and ocular inflammation. The distribution of the causes is shown in Table 4.

Causes of visual impairment were refractive errors in 4 students with 8 eyes (0.8\%) and immature developmental cataracts in 3 students with 4 eyes $(0.4 \%)$. These coexisted with other disabilities such as hearing and physical disabilities. No student had Usher's syndrome. There was a significant relationship between the blind students and ocular features, $\chi^{2} 169.69, \mathrm{P}<0.001$. Other ocular findings included nystagmus, depigmented irides / pigmentary retinopathy and other retinal disorders, and vernal conjunctivitis. Glasses were precscribed for all four with refractive errors and were corrected to normal vision using simple spherical and cylindrical lenses. The child with uncorrected aphakia could not be improved beyond hand movement at 1 meter with aphakic lenses and so needed low vision aids. All these cases of refractive errors had never used glasses.

\section{Discussion}

The students in special schools included those with hearing, visual, physical, intellectual and more than one disability or disabilities co-existing with blindness. There were more males than females in this study thereby giving a ratio of 1.4:1. The reason for this is not known. It may just be a coincidence. Comparison or similar findings of the ratio, with other studies is difficult since this study was carried out among children and schools housing all types of disabilities. The fathers' occupation was taken as a measure of the socio-economic class. The majority of the fathers belonged to the lower socio economic class of artisans, followed by farmers and the civil servants, among which various ocular abnormality was seen to be the highest. A similar occurrence was found among the normal school students of the same state where eye diseases were most prevalent among the lower socio-economic class [11].

The number of bilateral blindness was 22 (4.7\%). In addition, 2 unilateral blind eyes making a total of 46 blind eyes were seen. In Yemen, 45 (4.1\%) were found to be blind bilaterally while 115 (10.4\%) had blindness in one eye. The most common cause of blindness in our study was corneal scarring; majority of which was due to post measles keratopathy. Similarly, measles keratopathy were seen as the commonest cause of blindness among schools for the blind in Oyo State of Nigeria [12]. Others were buphthalmic 
Table 4. Distribution of Ocular Findings Among 472 Special Students ${ }^{\mathrm{a}}$

\begin{tabular}{|c|c|}
\hline Ocular Findings & Frequency (\%) \\
\hline \multicolumn{2}{|l|}{ Causes of bilateral blindness } \\
\hline \multicolumn{2}{|l|}{ Anatomic } \\
\hline \multicolumn{2}{|l|}{ Cornea scarring } \\
\hline Measles corneal opacity & $2(0.4)$ \\
\hline Measles keratopathy with anterior staphyloma & $2(0.4)$ \\
\hline Corneal opacity(unknown cause) & $2(0.4)$ \\
\hline Buphthalmos with decompensated cornea & $2(0.4)$ \\
\hline Decompensated keratoconus & $1(0.2)$ \\
\hline Corneal dystrophy & $1(0.2)$ \\
\hline \multicolumn{2}{|l|}{ Lens } \\
\hline Complicated cataract & $2(0.4)$ \\
\hline \multicolumn{2}{|l|}{ Retina } \\
\hline Maculopathy & $1(0.2)$ \\
\hline Toxoplasmosis & $1(0.2)$ \\
\hline \multicolumn{2}{|l|}{ Whole globe } \\
\hline Phthisis bulbi & $2(0.4)$ \\
\hline Congenital empty socket & $1(0.2)$ \\
\hline Eviscerated empty socket & $1(0.2)$ \\
\hline Congenital microphthalmos & $1(0.2)$ \\
\hline \multicolumn{2}{|l|}{ Refractive error } \\
\hline Uncorrected aphakia & $1(0.2)$ \\
\hline Pathological myopia & $1(0.2)$ \\
\hline \multicolumn{2}{|l|}{ Neurological } \\
\hline Cortical visual impairment & $1(0.2)$ \\
\hline Total bilateral & $22(4.7)$ \\
\hline \multicolumn{2}{|l|}{ Trauma (Unilateral blindness) } \\
\hline Optic atrophy & $1(0.2)$ \\
\hline \multicolumn{2}{|l|}{ Inflammation (Unilateral blindness) } \\
\hline Panuveitis & $1(0.2)$ \\
\hline \multicolumn{2}{|l|}{ Others (Not causing blindness) } \\
\hline Vernal conjunctivitis & $2(0.4)$ \\
\hline Depigmented irides and retinae & $10(2.1)$ \\
\hline Pigmentary retinopathy & $20(4.2)$ \\
\hline Nystagmus & $1(0.2)$ \\
\hline Normal eyes & $415(88.0)$ \\
\hline Total & $472(100)$ \\
\hline
\end{tabular}

${ }^{\mathrm{a}}$ Bilateral blindness $=22$ (4.7\%. C.I 2.7 - 6.5), I-VI=All blind eyes $=46$ (4.9\% C.I. 3.5 $6.2)$.

corneal opacities and corneal dystrophy. This was in con- trast to cataract, glaucoma and retinal disorders that were seen in Yemen to cause blindness [13]. However, this is unfortunate because these are preventable causes of blindness. The next group of causes of blindness was the whole globe disorders such as phthisis bulbi, microphthalmos, and enophthalmos. Congenital cataract and glaucoma, treatable causes, were the third most common diagnosis. The possibilities are the parents' ignorance of where to take the child for treatment, or the "inaccessibility" of eye care services either in terms of cost or availability of services. Fear of surgery or abandoning the child with no care have been seen in the authors practical experience as barriers to taking up surgery [14]. Our findings were similar to those seen in Cambodia where measles constituted 8.1\% of the avoidable causes, while cataracts and glaucoma were the common treatable causes with $22.6 \%$ and $4.8 \%$ respectively [15].

Cortical blindness was seen in only one student. This was a result of brain damage following cerebral malaria. Malaria is the commonest cause of febrile convulsions in our environment (Africa); the sequelae often being cortical blindness $[16,17]$. The co-existing challenges with blindness were hearing disability, carrying the highest proportion (67.2\%), and those with intellectual disabilities (23.3\%). In the study from west of Scotland, some of the students with blindness also had co-existing multiple disabilities [18]. Corneal scarring still remains the most common cause of childhood blindness in sub-Saharan Africa [3,19]. Visual impairment was caused by refractive error and cataract among 7 students with hearing disabilities. These compared to the Yemen findings of causes of low vision being refractive errors, keratoconus and retinal disorders. The other three were referred to the eye clinic for management of cataract Some barriers to proper treatment or prevention of the conditions could have been due to the parents' education and where to take the child for treatment, or the "inaccessibility" of eye care services either in terms of cost or availability of services. Fear of surgery or abandoning the child with no care have been seen in the authors experience as obstacles for treatment [14]. Refraction was performed and glasses were prescribed for four children. Refractive error was very low in our study as compared to the results from Nepal where refractive error constituted (40\%) of cases [20]. This could be due to the fact that their study was mainly done among students with intellectual disabilities unlike in ours that was conducted across children with all types of disabilities. Cortical blindness was seen in only one student. This was a result of brain damage following cerebral malaria [16, 17]. In our study, the retinal disorders were mostly the non-blinding types except for ocular toxoplasmosis as depigmented irides and depigmented retina were mainly seen. These were 
probably variants of ocular albinism. Retinal diseases (dystrophies) were also seen in Nepal as causes of blindness [20]. Surprisingly, retina diseases (dystrophies) were seen in east Africa to cause blindness [21]. Could this mean that childhood cataracts have been taken care of adequately or that there is accessible and affordable treatment for it in east Africa? Causes of retinal diseases like toxoplasmosis occurred from intrauterine life infections and the maculopathy was due to congenital abnormality of the macula. Some studies revealed that congenital toxoplasmosis have been found to be associated with severe visual impairment [22].

Sensory nystagmus was as a result of severe visual loss in an uncorrected aphakia. No student with strabismus was found. Pigmentary retinopathies were seen in $4.2 \%$ of the students. There was no case of Usher's syndrome seen as compared to the study by Onakpoya et al. where 1 case was found in a school for the deaf [23]. Gogate et al. found that hearing impaired students had low visions which were correctable after refraction [24].

Only one child was in need of low vision aids as compared with the study in Wales where low vision was present in $17 \%$ of the pupils. There was also a hundred percent need for glasses prescription in this study as against 50\% need in Wales where the burden of unrecognized visual impairment was studied among children in special schools [25]. Efforts at assisting children with disabilities are being made so that learning can be conducive. Introduction of information, computer and technology has been found to be of great help towards spelling, communication and writing [26].

\subsection{Conclusion}

The common ophthalmic conditions found included causes of blindness from corneal scarring and causes of visual impairment from cataract and refractive errors, and cortical visual impairment. These are avoidable. Health education, adequate nutrition, and immunization are required for prevention. Mandatory eye screening for children at birth, pre-school, and school age is advocated for early detection and treatment.

\section{Acknowledgments}

We hereby express our sincere gratitude to the head teachers and teachers of all the special education schools (mentioned above) in Osun State, Nigeria, involved in this study for their cooperation and assistance during the examination of the students as well as provision of necessary information from their records, personal contact on the fathers' occupation, and some of the causes of the disabilities. Special thanks to my mentor and teacher Linda
Lawrence MD who edited and reconstructed the terminologies during the write up.

\section{Footnotes}

Authors' Contribution: Michaeline Isawumi conceptualized, designed, analyzed and written the article. Folasade Akinsola edited and written.

Financial Disclosure: None. Funding/Support: None.

\section{References}

1. Oxford advanced learners dictionary. 6th edition. British Oxford press; 2000. p. 537.

2. Committee on the rights of the child. Rights of the nigeria child. A report on the implementation of the convention on the rights of the child by Nigeria. Geneva. 2005. pp.14-5.

3. New issues in childhood blindness. Community Eye Health. 2001;14(40):53-6. [PubMed: 17491932].

4. Akinsola FB, Ajaiyeoba AI. Causes of low vision and blindness in children in a blind school in Lagos, Nigeria. West AfrJ Med. 2002;21(1):63-5. [PubMed: 12081349].

5. Okoye OI, Aghaji AE, Ikojo IN. Visual loss in a school for the blind in Nigeria. Niger J Med. 2009;18(3):306-10. [PubMed: 20120652].

6. Mirdehghan SA, Dehghan MH, Mohammadpour M, Heidari K, Khosravi $M$. Causes of severe visual impairment and blindness in schools for visually handicapped children in Iran. Br J Ophthalmol. 2005;89(5):612-4. doi: 10.1136/bjo.2004.050799. [PubMed: 15834095].

7. Kasmann-Kellner B, Hille K, Pfau B, Ruprecht KW. [Eye and general illnesses in the public school for blind and visually handicapped students in Saarland. Developments in the last 20 years]. Ophthalmologe. 1998;95(1):51-4. [PubMed: 9531802].

8. Bhasin TK, Brocksen S, Avchen RN, Van Naarden Braun K. Prevalence of four developmental disabilities among children aged 8 yearsMetropolitan Atlanta Developmental Disabilities Surveillance Program, 1996 and 2000. MMWR Surveill Summ. 2006;55(1):1-9. [PubMed: 16437058].

9. Population of osun state based on projection of the 2006's national census figures at annual growth rate of $2.8 \%$. Federal Republic of Nigeria's Official Gazette. 2007;94(24).

10. International classification of diseases. 11. Geneva: World Health Organization; 1975.

11. Ajaiyeoba AI, Isawumi MA, Adeoye AO, Oluleye TS. Pattern of eye diseases and visual impairment among students in southwestern Nigeria. Int Ophthalmol. 2007;27(5):287-92. doi: 10.1007/s10792-007-9056-7. [PubMed: 17585376].

12. Mosuro AL, Ajaiyeoba AI, Bekibele CO, Eniola MS, Adedokun BA. Survey of low vision among students attending schools for the blind in Nigeria: a descriptive and interventional study. Middle East Afr J Ophthalmol. 2012;19(4):382-91. doi: 10.4103/0974-9233.102744. [PubMed: 23248540].

13. Bamashmus MA, Al-Akily SA. Profile of childhood blindness and low vision in Yemen: a hospital-based study. East Mediterr Health J. 2010;16(4):425-8. [PubMed: 20795428].

14. Vanneste GA. Practical guide for eye units in developing countries. ; 2001. pp.10-25.Breaking down barriers: How to increase the cataract surgical rate.

15. Sia DI, Muecke J, Hammerton M, Ngy M, Kong A, Morse A, et al. A survey of visual impairment and blindness in children attending four schools for the blind in Cambodia. Ophthalmic Epidemiol. 
2010;17(4):225-33. doi: 10.3109/09286586.2010.489250. [PubMed: 20642345].

16. Roman GC. The neurology of parasitic diseases and malaria, neurologic complications of systemic disease. Lifelong Learning in Neurology. 2011;17(1):113-33.

17. Osuntokun BO. Malaria and the nervous system. Afr J Med Med Sci. 1983;12(3-4):165-72. [PubMed: 6326550].

18. Bamashmus MA, Matlhaga B, Dutton GN. Causes of blindness and visual impairment in the West of Scotland. Eye (Lond). 2004;18(3):25761. doi: 10.1038/sj.eye.6700606. [PubMed:15004574].

19. Ntim-Amponsah CT, Amoaku WM. Causes of childhood visual impairment and unmet low-vision care in blind school students in Ghana. Int Ophthalmol. 2008;28(5):317-23. doi: 10.1007/s10792-0079134-x. [PubMed: 17898940].

20. Puri S, Bhattarai D, Adhikari P, Shrestha JB, Paudel N. Burden of ocular and visual disorders among pupils in special schools in Nepal. Arch Dis Child. 2015;100(9):834-7. doi: 10.1136/archdischild-2014-308131. [PubMed: 25900842].

21. Tumwesigye C, Msukwa G, Njuguna M, Shilio B, Courtright P, Lewallen $S$. Inappropriate enrollment of children in schools for the visually impaired in east Africa. Ann Trop Paediatr. 2009;29(2):135-9. doi:
10.1179/146532809X440752. [PubMed: 19460267].

22. Lipka B, Milewska-Bobula B, Idzik M, Marcinski P, Dunin-Wasowicz D, Kassur-Siemienska B, et al. [Visual and auditory impairment in children with congenital cytomegalovirus and Toxoplasma gondii infection]. Przegl Lek. 2002;59 Suppl 1:70-2. [PubMed: 12108080].

23. Onakpoya $\mathrm{OH}$, Omotoye OJ. Screening for ophthalmic disorders and visual impairment in a Nigerian school for the deaf. EurJ Ophthalmol. 2010;20(3):596-600. [PubMed: 20037903].

24. Gogate P, Rishikeshi N, Mehata R, Ranade S, Kharat J, Deshpande M. Visual impairment in the hearing impaired students. Indian J Ophthalmol. 2009;57(6):451-3. doi: 10.4103/0301-4738.57155. [PubMed: 19861747].

25. Woodhouse JM, Davies N, McAvinchey A, Ryan B. Ocular and visual status among children in special schools in Wales: the burden of unrecognised visual impairment. Arch Dis Child. 2014;99(6):500-4. doi: 10.1136/archdischild-2013-304866. [PubMed: 24281359].

26. Lidstrom $\mathrm{H}$, Hemmingsson $\mathrm{H}$. Benefits of the use of ICT in school activities by students with motor, speech, visual, and hearing impairment: a literature review. Scand J Occup Ther. 2014;21(4):251-66. doi: 10.3109/11038128.2014.880940. [PubMed: 24506197]. 